UDC $177+304.2$

LBC 87.6

\title{
THE CRISIS OF RECOGNITION IN THE CONTEXT OF SOCIAL EXCLUSION
}

\author{
Valeriya A. Kopaneva \\ Volgograd State University, Volgograd, Russian Federation
}

\begin{abstract}
The author suggests the idea of reflecting the experience of social exclusion and considers the problem faced by people, communities and social institutions, that is a crisis of recognition. Recognition is referred to as the process during which one subject formulates new knowledge about another and evaluates it, as a result of it a commonality arises between them. However, in the conditions of the new reality, the negative consequences of isolation are visible, which are expressed in the following forms: spatial disunity, alienation, lack of communication, lack of joint social practices, separation from the community, individualization and, as a result, non-recognition. The idea of isolation prevents recognition. Isolation implies isolation / autonomy from social contacts, difficulty in gaining new knowledge about other objects, which leads to a weakening of the mimetic aspect of recognition and an increase in the perception of the danger of the Other. At the same time, the idea of initiation, which involves crossing the border, is an integral part of recognition - this fact implies the presence of at least two spaces of different quality, that is why, it is necessary to observe the principle of horizontality. Spaces are not arranged hierarchically, in online practices there is no boundary between private and public spaces, respectively, if there is no priority of one space over another, then there is no need to give recognition. The lack of recognition leads the subject to disorientation: when it becomes difficult for him to evaluate and understand the processes occurring not only with him, but also in the external world. Thus, we conclude that online practitioners do not form communities and shared presence that prevents the expression of recognition.
\end{abstract}

Key words: recognition, isolation, community, representation, evaluation, initiation.

Citation. Kopaneva V.A. The Crisis of Recognition in the Context of Social Exclusion. Logos et Praxis, 2021, vol. 20, no. 2, pp. 89-94. (in Russian). DOI: https://doi.org/10.15688/lp.jvolsu.2021.2.11

УДК $177+304.2$

ББК 87.6

\section{КРИЗИС ПРИЗНАНИЯ В УСЛОВИЯХ СОЦИАЛЬНОЙ ИЗОЛЯЦИИ}

\author{
Валерия Андреевна Копанева \\ Волгоградский государственный университет, г. Волгоград, Российская Федерация
}

\begin{abstract}
Аннотация. В статье предлагается отрефлексировать опыт социальной изоляции и рассмотреть проблему кризиса признания, с которой столкнулись человек, сообщества, социальные институты. Под признанием имеется в виду процесс, в ходе которого один субъект артикулирует новое знание о другом и дает ему оценку, вследствие чего между ними возникает общность. Однако в условиях новой реальности отмечаются негативные последствия изоляции, которые выражаются в следующих формах: пространственная разобщенность, отчуждение, дефицит коммуникации, дефицит совместных социальных практик, отделение от сообщества, индивидуализация и, как следствие, дефицит признания. Идея изоляции препятствует получению признания, она предполагает отделение от социальных контактов, труднодоступность получения нового зна-

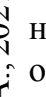
ния о других объектах, что приводит к ослаблению миметического аспекта признания и возрастанию идеи опасности Другого. В то же время для признания неотъемлемой частью является идея инициации, которая пространства и необходимо соблюсти принцип горизонтальности. Пространства не расположены иерархически, в онлайн-практиках нет границы между приватным и публичным, соответственно если нет приоритета одного пространства перед другим, то и нет необходимости давать признание. Его отсутствие приводит субъекта к дезориентации: ему становится сложно оценить и понять процессы, которые происходят не толь-
\end{abstract}




\section{ИЗОЛЯЦИЯ В ОТКРЫТОМ ОБЩЕСТВЕ}

ко с ним, но и во вне, в мире. Таким образом, мы приходим к выводу, что онлайн-практики не формируют общность и соприсутствие, а это препятствует выражению признания.

Ключевые слова: признание, изоляция, общность, репрезентация, оценка, инициация.

Цитирование. Копанева В. А. Кризис признания в условиях социальной изоляции // Logos et Praxis. 2021. - T. 20, № 2. - C. 89-94. - DOI: https://doi.org/10.15688/lp.jvolsu.2021.2.11

В 2020 г. человечество столкнулось с принципиально новым опытом, который нуждается в рефлексии, чтобы определить, как повлияли пандемия и изоляция на взаимодействие субъектов в рамках различных социальных практик.

Повлек ли опыт изоляции негативные последствия для человека? Да, и одним из таких последствий явился кризис признания, который связан с тем, что для индивида или коллектива получение признания стало труднодоступным по причине удаленности от тех пространств, практик и субъектов, которые способы такое признание осуществлять.

Несмотря на то, что сами практики не прекратились, а лишь стали в значительной своей части дистанцированными (онлайн), мы попытаемся показать, что в рамках изоляции, если понимать ее не в узком современном смысле, а обобщенно, субъект не получает полноценного опыта признания и, как следствие, испытывает его дефицит.

Признание - это процесс, в ходе которого один субъект артикулирует новое знание о другом и дает ему оценку, вследствие чего между ними возникает общность. В качестве основных черт признания можно назвать:

1) адресность (признание не существует автономно от своего объекта, который в силу принципа взаимности одновременно становится субъектом встречного признания).

2) оценочность (признание содержит ценностную характеристику своего объекта [Михайлов 2012, 86], в силу чего оно может быть положительным (признание-одобрение) или отрицательным (признание-осуждение);

3) интерпретация (воспроизводство буквального значения позволяет лишь подтвердить имеющееся знание об объекте, в то время как интерпретация позволяет извлечь новый смысл, который может стать основанием для признания);

4) конкретизация (процесс признания осуществляется по двум направлениям: поиск объекта - «кто признается?»; поиск основания - «за что признается?»);

5) редукция (в процессе признания сложный образ объекта приводится к более простому путем отбора одного или нескольких значимых признаков в качестве основания);

6) вербальность (необходимым условием для признания является словесная форма, поскольку только она может свидетельствовать о тех внутренних операциях мышления, которые провел субъект признания: лишь по речи можно идентифицировать оценку объекта, интерпретацию, адресность и т. д.).

Уже исходя из определения, можно наметить ряд проблем, с которыми сталкивается признание в условиях изоляции:

1) отсутствие непосредственного коммуникативного контакта с другим субъектом;

2) затруднение в получении нового знания о субъекте, чтобы артикулировать его;

3) невозможность дать оценку, поскольку новое знание о субъекте не получено;

4) отсутствие общности.

Поскольку в условиях изоляции выполнение данных условий встречает дополнительные затруднения, то повышается риск, что полноценного признания не произойдет. При этом индивид или коллектив как и прежде может располагать ресурсом признанности, то есть следами того признания, которые он получил в прошлом. Признанность, в отличие от признания, статична, то есть представляет собой совершившийся акт (символический капитал), в котором лишь откладываются, но не обновляются, а следовательно растрачиваются ранее накопленные информационные и ценностные ресурсы.

А. Кожев в своей работе «Введение в чтение Гегеля» также указывает на важность приобщения к другим: «Человек отличается от животного тем, что он - Гражданин (Burger), он может осуществиться как человек только принадлежа народу (Volk), организованному в Государство (Staat). Vermittlung (опосредование) - это по существу деятель- 
ность (l'action) в Обществе, опосредованная Обществом (dans et par); это настоящее Anerkennen (признание): человек признает другого человека человеком, будучи сам признан им в качестве такового. Только в другом и с помощью другого обретает человек Befriedigung (удовлетворение). В мире чистой природы и просто жизни нет Vermittlung (опосредования), потому что нет Общества (Volk, Staat), в котором индивиды «признавали» бы друг друга в их действительности и достоинстве. Итак, вне Общества Человек - всего лишь животное («духовное животное» - Bete Intellectuelle)» [Кожев 2003, 100]. Изоляция и онлайн-практики не позволяют сформировать или даже поддержать общность, поскольку не создают соприсутствия, а только допускают собрание индивидов в разных пространствах.

Реализация признания возможна лишь в обществе или в сообществе, хотя бы потому что в основе этого механизма лежит мимесис, что подчеркивал Р. Жирар на примере процесса обучения: «Отношение образец / ученик по определению исключает равенство, которое только и могло бы сделать соперничество возможным в глазах ученика. Ученик находится в том же положении, в каком находится верующий по отношению к божеству; он имитирует желания образца, но не способен признать в них аналог своих собственных желаний; короче говоря, он не понимает, что может “вторгнуться на территорию" образца, стать для него угрозой. Если это верно даже по отношению к взрослым, то уж тем более - по отношению к ребенку, к изначальному миметическому желанию» [Жирар 2010, 229]. Каждый акт признания, помимо субъекта и объекта, включает в себя ту фигуру, с которой может быть отождествлен тот, кого признают [Giorgini G., Irrera E. (ed.) 2017, 17].

В повести Ф.М. Достоевского «Село Степанчиково и его обитатели» миметический аспект признания представлен, когда умирает хозяин дома, генерал, и всю власть над домочадцами захватывает шут-приживал Фома Фомич Опискин, не обладающий никаким статусом, чтобы оправдать тот авторитет, который ему удалось установить в доме. У читателя возникают закономерные вопросы: «Как шут может завоевать такое признание?», «Почему герои видят в Фоме того, кто может занять место генерала?» Мимесис раскрывает данную загадку: Фома Фомич был свидетелем проявления генеральской власти, подражал ему и после его смерти стал единственным, кто мог перенять хозяйские функции [Достоевский 1988].

Артикуляция нового знания о Другом в ходе признания осуществляется посредством такого действия, как персонификация абстрактного понятия или культурного символа.

Субъект признания производит ментальное размыкание через привязку конкретного образа к обобщенной категории (изначально абстрактное понятие само по себе закрыто, поскольку оторвано от опыта человека). Таким образом, благодаря признанию происходит двойное обогащение опытом - одновременно конкретным и абстрактным.

В романе Ф.М. Достоевского «Бесы» представлен пример такого признания, которое персонифицирует культурный символ, а именно эпизод признания Ставрогина в качестве Ивана-Царевича во второй части романа:

-<..> Ну-с, тут-то мы и пустим... Кого?

- Кого?

- Ивана-Царевича.

- Кого-о?

- Ивана-Царевича; вас, вас!

Ставрогин подумал с минуту.

- Самозванца? - вдруг спросил он, в глубоком удивлении смотря на исступленного. - Э! так вот наконец ваш план [Достоевский 1990, 395].

Верховенский выражает абстрактную идею через символ Ивана-Царевича, наделяя этим именем Ставрогина, чтобы признать его в качестве потенциального вождя, который «скрывается». Однако Ставрогин распознает в этом символе обозначение другой идеи «самозванства» - и не дает Верховенскому встречного признания.

Признание - это переход количественного изменения в качественное [Hanhela 2014, 59-60], когда набор фактов преобразуется через концептуализацию в формулу признания: персона подбирается к понятию или понятие к персоне.

Почему Верховенский вообще признает Ставрогина? Потому что Ставрогин, с одной стороны, является частью его круга, так как воспитывался отцом Верховенского с восьми 
лет, с другой стороны, он воспринимается как личность, для которой свойственна особая поведенческая модель, отличающаяся от общепринятой.

Таким образом, можно сформулировать парадокс признания: для того, чтобы быть признанным, лицу необходимо пребывать в составе группы (сообщества), поскольку лишь коллективно могут быть выработаны критерии и процедуры признания, но при этом требуется, чтобы сама группа опознавала его не просто как свой атрибут, а с относительной автономией от себя.

Ожидания признания обрамляются конкретным нормативным порядком, институциональной системой, которая, в свою очередь, является временным эффектом конфликтов между группами [Ivković 2016, 112]. Однако в условиях изоляции становится проблематичным само нахождение в какой-либо группе изза пространственной разрозненности. Набор людей в разобщенных топосах не является группой. В случае, если коллектив не формируется, индивид не способен проявить себя ни в качестве участника группы, ни в качестве того, кто предъявляет этой группе свой творческий продукт; как следствие, реального признания не происходит.

Соответствующим образом мы можем выделить два необходимых элемента признания:

1. (Ре)презентаиия. Один субъект обладает способностью и готовностью представить свой творческий продукт другому, чтобы получить оценку и обратную связь. П. Рикер указывает на социотворческую функцию репрезентаций: «Эта связь между репрезентациями и социальными практиками выражается в роли символического посредника, которую играют репрезентации, когда у социальных практик имеется определенная цель установление социальной связи и соответствующих ей модальностей идентичности. Следовательно, репрезентации являются не беспочвенными идеями, движущимися в автономном пространстве, а, как мы только что сказали, символическими посредниками, содействующими установлению социальной связи; они и символизируют идентичности, сообщающие в ходе своего установления определенную конфигурацию этим социальным связям. И наоборот, следует признать, что социальные идентичности и социальные связи не имеют своей природы, а только формы осуществления» [Рикер 2010, 130]. В ситуации изоляции возможности для репрезентаций резко сократились, что приводит к тому, что социальные связи либо не формируются, либо являются слабыми и неустойчивыми.

2. Оиенка. Субъект признания одновременно становится его объектом: он дает признание и в этот же момент претендует на признание в качестве признающего лица. Однако, если признающий не получает статуса, то и сам акт признания недействителен, поскольку нарушен принцип взаимности: «Оно представит собой прежде всего сторону неравенства обоих [самосознаний] [то есть двух людей, которые борются за признание] или распадение среднего термина [представляющего собой обоюдное признание] на крайние [две противные стороны], которые, как крайние, противоположны друг другу и из которых один есть только признаваемое, другой - только признающее. [Поначалу человек, который хочет заставить другого признать себя, со своей стороны не выражает ни малейшего желания признавать его. Если он победит, признание вовсе не будет взаимным: победителя признают, но он не признает того, кто его признал]» [Кожев 2003, 18].

Таким образом, признание предполагает свободную сменяемость статусов:

a) субъект 1 артикулирует признание объекта 1 ;

б) объект 1 переходит в статус субъекта 2, а субъект 1 становится объектом 2, который получает признание.

Признание - это инициация (трансгрессия), после которой субъект обретает новое качество, отсутствующее в предыдущем опыте. Появление этого нового качества невозможно без участия Другого как открывателя неизвестного.

Как отмечает А. ван Геннеп, «...иногда инициация совершается за один раз, иногда поэтапно. Там, где посвящаемый рассматривается как мертвый, его “воскрешают”, учат жить, но иначе, чем в детстве» [Геннеп ван 1999, 73].

Исходя из этого, существуют два уровня практик признания:

1. Первичные (признание-испытание) - социальные практики, которые направ- 
лены на проверку качеств субъекта, его компетенций (например, практика представления и публичной защиты диссертационного исследования, сценический дебют, первая выставка художника, первое публичное выступление музыканта, выдвижение кандидатуры на выборах и т. п.).

2. Вторичные (признание-посвящение) - социальные практики, направленные на то, чтобы присвоить субъекту новый статус (присуждение ученой степени, награждение победителя, инаугурация и т. д.).

Идея инициации предполагает преодоление границы - этот факт говорит о том, что необходимо наличие как минимум двух разных по качеству символических пространств. Однако в онлайн-практиках не происходит пространственного перемещения и разделения (стирается граница между публичным и приватным), что препятствует инициации. Пространства не расположены иерархически, но если отсутствует приоритет одного пространства перед другим, то нет и необходимости давать признание.

Таким образом, практика изоляции прежде всего противоречит идее символического обмена, что, в свою очередь, является препятствием для признания. Изоляция порождает ослабление социальных контактов, что приводит к угасанию миметического аспекта признания и возрастанию идеи опасности Другого.

Признание необходимо для ориентации в социальном пространстве, для формирования и подкрепления ценностных предпочтений, которые позволили бы субъекту осуществлять жизненный выбор, однако условия социальной изоляции сокращают возможности и для (ре)презентации творческого продукта, и для его оценки, что приводит к потере ориентиров и невозможности дать оценку происходящему.

\section{СПИСОК ЛИТЕРАТУРЫ}

Геннеп ван 1999 - Геннеп А. ван. Обряды перехода. Систематическое изучение обрядов. М.: Восточная литература РАН, 1999.

Достоевский 1988 - Достоевский Ф.М. Село Степанчиково и его обитатели // Собрание сочинений. В 15 т. Т. 3. Ленинград: Наука, 1988.
Достоевский 1990 - Достоевский Ф.М. Бесы // Собрание сочинений. В 15 т. Т. 7. Ленинград: Наука, 1990.

Жирар 2010 - Жирар Р. Насилие и священное. Изд. 2-е, испр. М.: Новое литературное обозрение, 2010.

Кожев 2003 - Кожев A. Введение в чтение Гегеля. СПб.: Наука, 2003.

Михайлов 2012 - Михайлов И.А. «Борьба за признание». Идея признания в социально-критической теории А. Хоннета // Западная философия конца XX - начала XXI в. Идеи. Проблемы. Тенденции. М.: ИФРАН, 2012.

Рикер 2010 - Рикер П. Путь признания. Три очерка. М.: РОССПЭН, 2010.

Giorgini G., Irrera E. (ed.) 2017 - Giorgini G., Irrera E. (ed.) Roots of Respect. A Historic-Philosophical Itinerary. Berlin; Boston: Walter de Gruyter, 2017.

Hanhela 2014 - Hanhela T. Educational Perspectives on Recognition Theory. Oulu: University of Oulu, 2014.

Ivković 2016 - Ivković M. The Habermasian Foundations and Aims of Axel Honneth's Theory of Recognition // Idéias. Vol. 7, № 2. P. 99-122.

\section{REFERENCES}

Gennep A. van, 1999. Rites of Passage. Systematic Study of Rites. Moscow, Vostochnaya literatura RAN.

Dostoevsky F.M., 1988. The Village of Stepanchikovo and its Inhabitants. Sobranie sochinenij. $V 15 t$. T. 3. Leningrad, Nauka Publ.

Dostoevsky F.M., 1990. The Possesed. Sobranie sochinenij. V15 t. T. 7. Leningrad, Nauka Publ.

Girard R., 2010. Violence and the Sacred. Moscow, Novoe literaturnoe obozrenie Publ.

Kojeve A., 2003. Introduction to the Reading of Hegel. Saint Petersburg, Nauka Publ.

Mikhailov I.A., 2012. "Struggle for recognition". The Idea of Recognition in the Social-Critical Theory of A. Honnet. Zapadnaya filosofiya konca XXnachala XXI v. Idei. Problemy. Tendencii. Moscow, IFRAN.

Ricouer P., 2010. The Path of Recognition. Three Essays. Moscow, ROSSPEN Publ.

Giorgini G., Irrera E. (ed.), 2017. Roots of Respect. A Historic-Philosophical Itinerary. Berlin; Boston, Walter de Gruyter Publ.

Hanhela T., 2014. Educational Perspectives on Recognition Theory. Oulu, University of Oulu.

Ivković M., 2016. The Habermasian Foundations and Aims of Axel Honneth's Theory of Recognition. Idéias, vol. 7, no. 2, pp. 99-122. 


\section{ИЗОЛЯЦИЯ В ОТКРЫТОМ ОБЩЕСТВЕ}

\section{Information About the Author}

Valeriya A. Kopaneva, Candidate for a Degree, Department of Philosophy, Volgograd State University, Prosp. Universitetsky, 100, 400062 Volgograd, Russian Federation, leravalera5@mail.ru, https://orcid.org/0000-0001-8656-236X

\section{Информация об авторе}

Валерия Андреевна Копанева, соискатель кафедры философии, Волгоградский государственный университет, просп. Университетский, 100, 400062 г. Волгоград, Российская Федерация, leravalera5@mail.ru,https://orcid.org/0000-0001-8656-236X 